\title{
FÍSICA MODERNA E CONTEMPORÂNEA NA FORMAÇÃO DE LICENCIANDOS EM FÍSICA: NECESSIDADES, CONFLITOS E PERSPECTIVAS
}

\section{Modern and contemporary physics in Physics teacher preparation: necessities, conflicts and perspectives}

\author{
Mikael Frank Rezende Junior ${ }^{1}$ \\ Frederico Firmo de Souza Cruz ${ }^{2}$
}

Resumo: O presente artigo tem como objetivo promover uma discussão sobre as perspectivas de licenciandos em Física quanto à introdução de tópicos e temas de Física Moderna e Contemporânea no Ensino Médio, contrapondo a formação inicial desses licenciandos e a realidade escolar vivida por eles enquanto estagiários e/ou docentes. Os dados foram obtidos por meio de entrevistas semiestruturadas realizadas em três instituições públicas de Ensino Superior, duas no estado de Santa Catarina e uma no estado de Minas Gerais, entre os anos de 2002 a 2007. Os resultados deste trabalho sugerem a ampliação da discussão sobre a inserção de Física Moderna e Contemporânea no Ensino Médio, sobretudo no âmbito da formação inicial no que tange à transposição de conteúdos e metodologias do Ensino Superior para a escola básica.

Palavras-chave: Física moderna e contemporânea. Formação de professores de Física. Ensino Médio.

\begin{abstract}
This paper aims to bring to the debate the views and perspectives of Physics undergraduates concerning the introduction of topics and themes of Modern and Contemporary Physics in High School. We pay special attention to the conflict between their initial preparation and the reality of school, either as trainees or teachers. The data was obtained through semi-structured interviews conducted in three public universities, two in Santa Catarina State and one in Minas Gerais State, between the years 2002 and 2007. The conclusions of this work suggest that the debate about the insertion of Modern and Contemporary physics in High School should be expanded mainly into the initial preparation of physics teacher with respect to transfer of content and methodologies from higher education to basic school.
\end{abstract}

Keywords: Modern and contemporary Physics. Physics teachers preparation. High School level.

\footnotetext{
${ }^{1}$ Licenciado em Física. Doutor em Educação Científica e Tecnológica. Docente, Instituto de Ciências Exatas, Universidade Federal de Itajubá (UNIFEI). Itajubá, MG. <mikael@unifei.edu.br>

${ }^{2}$ Físico. Doutor em Física Nuclear. Docente, Departamento de Física, Universidade Estadual de Santa Catarina (UFSC). Florianópolis, SC. < fredfirmo@gmail.com>

${ }^{1}$ Avenida BPS, n. 1303

Pinheirinho - Itajubá, MG

37.500-903 


\section{Introdução}

Dos objetivos apregoados pela legislação educacional vigente (BRASIL, 1996), devese admitir, no Ensino Médio (EM), independentemente da interpretação dada, a necessidade de se contemplarem alguns aspectos básicos da Física, permitindo não somente uma preparação para o Ensino Superior, mas também para uma intervenção mais crítica para se pensar e interpretar o mundo. Porém, assim como diversas outras áreas da educação básica, o ensino de Física passa por dificuldades no que tange a sua atualização/renovação, regido pelas diretrizes legais de ensino (RICARDO, 2002; RICARDO e ZYLBERSTAJN, 2002).

O que se denominou acima como aspecto básico é constituído de um corpo de conhecimentos da Física que permite uma discussão mais ampla da Ciência e Tecnologia associadas, tanto para uma familiarização com fenômenos naturais e artefatos tecnológicos contemporâneos quanto para a apropriação de referências conceituais na legitimação de discursos. Com esta compreensão, os conhecimentos científicos e tecnológicos, quando abordados de forma adequada na escola, devem dotar o indivíduo de um instrumental de pensamento e de leitura de mundo para que se interprete e se transforme a sociedade. Porém, aparentemente, é no momento de cumprir esta função, de formação do homem-cidadão, que a escola entra em contradição, pois os conteúdos e metodologias adotados não têm atendido às necessidades dos indivíduos, qual seja: capacitá-los para uma intervenção efetiva e ativa na sociedade contemporânea. Dentre as inúmeras necessidades educacionais, imediatas ou de médio e longo prazo, justifica-se a importância da incorporação de temáticas envolvendo conhecimentos além da fronteira dos clássicos tradicionalmente desenvolvidos há várias décadas no EM, por exemplo, a Física e as Tecnologias desenvolvidas depois de 1900.

Para o Ensino Médio meramente propedêutico atual, disciplinas científicas, como a Física, têm omitido os desenvolvimentos realizados durante o século XX e tratam de maneira enciclopédica e excessivamente dedutiva os conteúdos tradicionais. Para uma educação com o sentido que se deseja imprimir, só uma permanente revisão do que será tratado nas disciplinas garantirá atualização com o avanço do conhecimento científico e, em parte, com sua incorporação tecnológica. (BRASIL, 1999, p. 209)

Entretanto, atualmente não é mais necessário remeter-se a extensas justificativas para se delinear a discussão sobre a necessidade da introdução de conceitos da Física do século XX no EM em caráter emergencial, e de dispor, aos alunos que não seguirão carreiras científicas, elementos de Física Moderna e Contemporânea (FMC), visto que excelentes trabalhos já têm caracterizado tal necessidade (LOBATO e GRECA, 2005; OSTERMANN e RICCI, 2005; GRECA, 2000), como: a questão curricular com a investigação dos conteúdos específicos passíveis de tratamento no espaço escolar médio (OSTERMANN e MOREIRA, 2000), a busca por metodologias adequadas para a FMC na educação básica (OSTERMANN e RICCI, 2004; TERRAZZAN, 1994; GIL e SOLBES, 1993; FISCHLER e LICHTFELDT, 1992; ARONS, 1990), bem como aplicações pontuais e as dificuldades encontradas nesses processos (MACHADO e NARDI, 2007; REZENDE JR, 2006; MOTA, 2000; OSTERMANN, 1999). 
Embora pesquisas em Ensino de Física tenham se dedicado fortemente às temáticas descritas anteriormente, buscaremos, na presente análise, não dissociar as peculiaridades conceituais das temáticas envolvendo FMC e a formação dos professores frente a essas, visto que serão estes os que terão o acesso mais imediato aos alunos da educação básica e, consequentemente, aqueles que tomarão as principais decisões, pois passada mais de uma década de pesquisa, a dificuldade e lentidão da inserção destes tópicos no EM indicam a presença de obstáculos marcantes, dentre eles: a falta de um objetivo mais claro do que se quer com esta inserção, falta de material didático adaptável e dificuldades estruturais no processo de formação dos professores.

Sendo assim, o ponto principal a ser tratado neste estudo será o de que os objetivos da formação em FMC não estão claros nas estruturas das Instituições de Ensino Superior (IES), e este fato reflete diretamente na visão de licenciandos sobre essa temática. Ainda no que concerne aos objetivos deste trabalho, é importante frisar que, em nossa análise, nos preocupamos com a discussão sobre o par formação/informação ${ }^{3}$. Isto se deve, sobretudo, ao fato de que notamos, em algumas propostas e aplicações, que a falta de clareza quanto aos objetivos tem como sintoma a presença de um conflito entre dar um tratamento mais formativo ou mais informativo aos tópicos e temas de FMC no EM. Entendemos aqui o formativo como a escolha de temas e tópicos e de abordagens que almejam fornecer uma base conceitual estruturada que dê ao aluno da escola básica os instrumentos para pensar e, sobretudo, modelar temas da FMC. Por outro lado, entendemos o informativo como o tratamento que se destina, sobretudo, a uma ampliação despretensiosa da "cultura" científica dos estudantes, sem uma preocupação mais efetiva com os aspectos conceituais nem com os processos de modelização dos fenômenos que envolvem a FMC.

\section{Metodologia e público}

$\mathrm{Na}$ busca por uma compreensão sobre como licenciandos e professores de Física vislumbram a pertinência e as pretensas características (formativa ou informativa) dos conceitos da Física do século XX para a escola média, foram entrevistados, nesse estudo, 31 licenciandos em Física de instituições públicas, sendo 15 entrevistados em duas IES do Estado de Santa Catarina (I1 e I2) entre os anos de 2002 a 2004 ${ }^{4}$, e 16 entrevistados em uma IES no estado de Minas Gerais (I3) durante os anos de 2006 e 2007.

Para esta análise, optou-se pelo enfoque qualitativo, com a realização de entrevistas semiestruturadas, por possibilitar um maior aprofundamento do fenômeno em questão, não somente pelo pesquisador encontrar-se inserido no contexto, mas também pelo fato de os

\footnotetext{
${ }^{3}$ Uma discussão preliminar sobre o par formação/informação foi apresentada em Rezende Jr. e De Souza Cruz (2005).

${ }^{4}$ Quando do término da realização das entrevistas, os dois cursos eram os únicos voltados à formação de professores de Física no Estado de Santa Catarina.
} 
elementos, entrevistador e entrevistados, pertencerem a um processo que se desenvolve dinamicamente. O contato direto do pesquisador com o fenômeno estudado e o ambiente no qual está situado permitem que os dados obtidos descrevam as perspectivas dos sujeitos envolvidos. Na entrevista semiestruturada não há uma imposição rígida na ordem das questões, e o entrevistado fala sobre os temas conforme as informações de que dispõe (LÜDKE e ANDRÉ, 1986). A opção por esse tipo de entrevista se deve, também, ao fato de a presença do pesquisador ser valorizada, ao mesmo tempo em que oferece liberdade ao informante.

$\mathrm{Na}$ I1, os dez entrevistados tiveram ${ }^{5}$, durante a sua formação regular superior, três disciplinas que compõem o quadro de horas dedicadas ao estudo da Física do século XX. São elas: Laboratório de Física Moderna (72h/a), Estrutura da Matéria I (108h/a) e Estrutura da Matéria II (108h/a), além das disciplinas que apresentam introdutoriamente tópicos de FMC no seu programa, como Física Geral IV ${ }^{6}$. No curso de licenciatura da I2, os cinco entrevistados tiveram, durante a sua formação, duas disciplinas voltadas à Física do século XX; são elas: Física Moderna I, com 72h/a, e Física Moderna II, com 60h/a. Já no curso de Licenciatura em Física da I3, onde foram registradas 16 entrevistas, duas disciplinas, Física Quântica ( 90 h/a) e Laboratório de Física Moderna (60 h/a), compõem o quadro de horas destinadas à FMC, sendo que, em sua estrutura ementária, assim como na I1, há introdução de tópicos de FMC no programa da disciplina Física Geral 4.

É relevante ressaltar que todos os entrevistados encontravam-se praticamente no último ano de curso, sendo que 22 dos 31 entrevistados (aproximadamente 71\%) já exerciam a função de docentes de Física no EM, em escolas da rede estadual e particular, mesmo antes de concluírem seus respectivos cursos de formação inicial. Para este fato não há nenhuma surpresa, em face do grande déficit de professores nesta área.

Para cada um dos entrevistados, foram realizadas quatro perguntas estruturais, que poderiam se desmembrar em outras, em função do andamento da entrevista, e que serão descritas, comentadas e analisadas a seguir. Como forma de organização, a simbologia utilizada para as entrevistas foi a seguinte: um conjunto de três letras de forma aleatória para o entrevistado e a identificação da IES, como o exemplo: (SSA - I1).

\section{Análise e resultados}

Ainda que esteja fortemente sugerido na legislação vigente e nas pesquisas em Ensino de Física, a primeira questão proposta aos entrevistados versava sobre o posicionamento de licenciandos em relação à introdução de FMC no EM. Basicamente, tal questionamento centrouse na formação dos licenciados e se os mesmos se sentem preparados para trabalhar com temas referentes à FMC na Educação Básica ou se, independentemente de terem uma formação

\footnotetext{
${ }^{5} \mathrm{O}$ tempo verbal utilizado é no passado visto que pequenas alterações curriculares foram realizadas nas IES desde a coleta de dados até a confecção final deste artigo.

${ }^{6}$ A referida disciplina contempla noções de relatividade em sua ementa, mas não é possível computarmos uma carga horária para cada tópico.
} 
adequada para tal, estariam propensos a trabalhar e discutir, com seus atuais e/ou futuros alunos do EM, temas e tópicos relacionados à Física do século XX.

Nos depoimentos referentes a esta questão, $67,7 \%$ dos entrevistados declararam-se preparados para tratar assuntos de FMC no EM; $13 \%$ se achavam parcialmente preparados, e 19,3\% dos entrevistados declararam não possuírem uma formação adequada para tratarem de tais assuntos na escola básica.

Apesar do reconhecimento de algumas dificuldades formativas frente aos tópicos e temas de FMC, a idéia de levar esses temas à escola média pelos licenciandos é numericamente expressiva, sendo que $90,3 \%$ dos entrevistados mostraram-se propensos e interessados em discutirem, no EM, temas e tópicos de FMC, ainda que alguns se sintam despreparados para tal tarefa. Contudo, apesar de expressivo, o número apresentado não pode ser o único parâmetro para qualquer tipo de análise, mas traz indicativos interessantes para esta pesquisa.

Sobre o ponto apresentado acima, os entrevistados explanaram que, apesar do potencial, da vasta aplicação e da presença da FMC na sociedade contemporânea, há um longo trabalho a ser feito quanto à abordagem sob a qual lhes são apresentados esses temas nos seus cursos de formação, e, consequentemente, quanto a seu possível tratamento na escola média. Algumas falas explicitam esse posicionamento recorrente:

"Existe uma grande diferença entre teoria e prática. Aqui nos ensinam a teoria, ou seja, como fazer, mas fazer é outra história. O que precisávamos mesmo é de exemplos na prática". (CBB - I1)

"Os professores da universidade precisam dar o exemplo, pois eles nos dizem o que fazer, mas não farem". (DBB - I1)

"Não podemos ensinar esses assuntos como nos ensinaram [...]". (ESC - I1)

"Acho que seria legal ensinar fazer aquela história de mostrar a relatividade do tempo. Aquilo é show! Mas não dá para faz̧er debulhando as equações e esperando que os alunos vão se esforçar para entender do mesmo jeito que nós temos que fazer aqui na faculdade”. (EEE - I3)

"Minha supervisora me cobrou isso [efeito fotolétrico] porque cain em um vestibular de São Paulo. Dai en pensei: como en vou fazer isso para a molecada sem cair naquelas fórmulas? [...]”. (AWW - I2)

As afirmações acima, para além do justificado apelo, acabam por remeter a outro problema, não menos importante, que é a natureza conceitual diferenciada dos objetos da FMC em relação aos objetos clássicos. O objeto quântico, por exemplo, possui uma natureza conceitual diferenciada daquela do objeto clássico, diferenças estas que aparecem tanto nos pressupostos epistemológicos e na linguagem matemática, quanto nas perguntas diferentes que redefinem o objeto de estudo como um ente quântico. Assim, da mesma forma que ficou evidenciado na fala dos entrevistados, deve-se soar o alerta de que a mera tentativa de enquadrar os temas de FMC em moldes didático-metodológicos tradicionais contribuirá apenas para adicionar temas diferentes de Física, sem, contudo, tocar na parte mais sensível que é a necessidade de redefinir o objeto a ser estudado. Isso implica rever não só o que ensinar, mas 
também a concepção de Ensino de Ciência e de Ciência, conforme lembrado por dois entrevistados.

"Trabalhando assuntos de Física Moderna, os alunos do Ensino Médio poderiam ter uma visão melhor do que é a Ciência”. (CCC - I1)

"Se eu mostrasse para eles [alunos do EM] como foi importante aqueles trabalhos do início do século [XX], talvez. eles entendessem melhor como a ciência funciona, ao invés de ficarem me perguntando por que é que se gastou tantos milhöes para mandar o Marcos Pontes para o espaço". (FCB-I3)

Nas declarações acima, fica evidenciada a necessidade de rever a concepção de ciência trazida pelos estudantes no EM e, conjuntamente, de explicitar que vários aspectos da vida social e do cotidiano estão ligados a fenômenos de natureza quântica, seja nas aplicações tecnológicas, seja nos fenômenos naturais, mas que dificilmente são reconhecidos como tal.

As falas abaixo sintetizam a expressão de vários entrevistados:

"A Física Moderna parece tão distante, mas não está. E têm exemplos no cotidiano, como a radiação solar, as lâmpadas de neon". (WPP - I2)

"[...] isso sem falar que esse gravador digital que você está usando agora para me entrevistar, a tela do notebook [...]. O mais bacana é ver que tudo aquilo que os professores ensinam de fotossintese tem uma explicação na Física Moderna”. (MDC - I3)

Porém, é comum que os estudantes de Física e professores associem fenômenos quânticos a coisas inatingíveis, longe da sensibilidade e do nosso dia-a-dia. E, diga-se de passagem, que os fenômenos quânticos são considerados inatingíveis tanto por se referirem a um mundo atômico e subatômico, como pela sua teoria, que é envolta em um grande "mistério" e encoberta pelo seu formalismo não trivial.

“[...] precisamos admitir que nossos alunos não estão acostumados com as abstrações”. (AAA - I2)

"Eu gostaria muito de discutir, por exemplo, a questão da dualidade onda-corpúsculo [...]. Mas é muito abstrato para eles, para mim, por exemplo, sempre foi, e eu acho que passaria por doido se tentasse fazer algo do tipo". (BBB - I1)

As declarações acima expressam as idéias de muitos entrevistados, em alguns de forma implícita, e que podem ter esteio na tradição do Ensino de Física. Enquanto a clássica sequência em espiral de Física 1, 2, 3, 4, Mecânica Racional e Eletromagnetismo foi transplantada para o EM e tem uma longa tradição de conteúdos básicos na formação de professores; no caso da FMC, a natureza do seu objeto não permite que haja uma transposição do mesmo tipo. Em particular nos aspectos relacionados com a estrutura da matéria, a natureza ampla e a riqueza de discussão conceitual seriam por demais sacrificadas se sofressem meras simplificações, ou seja, tentar adaptá-la ao modelo teoria-lista de exercícios comuns de simples aplicação de fórmulas pode tornar a FMC, no EM, um conteúdo meramente informativo ou deturpado. 
E embora já questionado por pesquisadores, o ensino tradicional tem um forte argumento a seu favor: a impossibilidade temporal de tratar todos os aspectos e ramificações da Física. Esta linearização seria assim, segundo seus defensores, a forma mais ordenada e rápida de se alcançarem os conhecimentos mínimos necessários de Física. Seu histórico mostra também que, apesar dos críticos, este paradigma de ensino tem conseguido formar bons físicos e engenheiros ao longo dos anos. Contudo, apesar deste argumento quase secular, é preciso esclarecer que este sistema tem funcionado, porém, prioritariamente para futuros físicos e engenheiros, pois geralmente não é para estes um caso terminal; em geral, ele é acompanhado de outras atividades extraclasse, tais como trabalhos de iniciação científica e de estágio. Além disso, a formação final para os físicos só vai ocorrer com o mestrado e doutorado, onde se espera que consigam fazer as conexões necessárias entre os fenômenos que estiverem pesquisando e todo o arsenal teórico e experimental adquirido nos cursos de formação inicial. Para aqueles que defendem essa linearização secular, cabe a seguinte pergunta: e para aqueles que seguirão outras carreiras ou terão, no EM, o término de sua educação básica?

Retomando as entrevistas, um fato marcante, durante o processo, foi a tendência de alguns entrevistados de condicionarem um possível sucesso quanto à implementação de temas relativos à FMC à disponibilidade de recursos didáticos. Tal ponto foi aqui explicitado pois não havia nenhuma menção direta a esse assunto em nenhuma das perguntas propostas. Algumas falas foram selecionadas para expressar essa observação:

"Seria necessário equipamentos como internet, vídeos, etc". (ABC - I1)

"Sem recursos como filmes e computadores seria muito difícil a aplicação desses tópicos". (APP - I1)

"Vi naquela disciplina de Informática na Educação uma simulação bacana de efeito fotoelétrico. Se na escola que eu to fazendo estágio tivesse computadores funcionando para os alunos eu iria usar aquilo". (JJJ - I3)

Para esta análise, é importante ressaltar que todas as menções feitas em relação à potencialidade do vídeo, simulações computacionais e congêneres provieram dos entrevistados das I1 e I3. Tal observância pode ter esteio em disciplinas anteriormente cursadas pelos entrevistados, onde é notória, por meio das ementas e programas das referidas disciplinas, uma preocupação com o uso fluente de múltiplos recursos: textos impressos, projetores, bases de dados, filmes, TV, e páginas da web, além da utilização sistemática de multimeios para a seleção, adaptação e produção de materiais didáticos alternativos para o EM. Trabalhos recentes (MACHADO e NARDI, 2007), inclusive, têm indicado bons resultados na utilização de sistemas hipermídia para o ensino e conceitos de FMC. Na I2, nenhuma disciplina dessa natureza faz parte da estrutura curricular obrigatória, fato esse que se reflete nas respostas dos entrevistados advindos dessa instituição.

A segunda questão proposta ao grupo de entrevistados buscava extrair qual característica (formativa ou informativa) de tais temas deve ser trabalhada no EM. Uma grande parcela dos entrevistados (64,5\%) fez menção à possibilidade de intervenções somente informativas. Nesta perspectiva, foi ressaltada a deficiência na formação dos alunos do EM frente a conceitos e aplicações matemáticas. 
Rezende Junior, M. F; De Souza Cruz, F. F.

"Só desse jeito [informativa], pois os alunos têm muitos problemas com a Matemática". (CCC - I1)

"Com a Matemática que nós pegamos os alunos no $2^{\circ}$ grau, só informativo mesmo”. (SSA - I1)

"Os caras [alunos do EM] chegam aqui muito ruins. A gente tem que dar aula de matemática fundamental. Não é nem matemática básica [...] Se fosse en já ficaria feliæ: Para esses caras não dá pra ir além das matérias que saem na Superinteressante [...] sem matemática alguma”. (JPD - I3)

Após a análise da segunda pergunta proposta, explicita-se aqui que os entrevistados manifestaram um entendimento confuso do que seja informativo, visto que o termo formativo foi utilizado direta e indiscriminadamente, na maioria das vezes, como a ênfase dada ao desenvolvimento do ferramental matemático.

Alguns entrevistados também fizeram menção à monotonia das aulas de Física ministrada por eles, e que de maneira informativa "a aula deixa de ser cansativa" (ABC - I1), ou que esse tipo de abordagem "pode tornar o aprendizado mais agradável' (PMM - I2), o que reforça a ideia de uma formação tópica e informativa como alento à exaustão provocada pelas aulas de Física. Porém, neste campo, foram detectadas muitas divergências, ressaltadas nas falas abaixo:

"Para que os alunos possam entender reportagens referentes a esses temas, eles não podem ter somente informacões, porque senão não conseguirão avaliar ou opinar sobre elas". (GGG - I1)

"Devido à importância atual desses assuntos, acho que só as informacõoes por si só não dão conta de mostrar tudo que deve ser mostrado". (DBB - I1)

“Aulinhas só contando 'bistorinhas' do tipo das que aparecem nas propagandas e nas revistinhas, os alunos acham legais no início, mas não dão muita bola [...] Se não tiver uma continha, uma equação, uma 'parada' estruturada como nos livros, eles acham que aquilo é ficção científica e não física". (RRI - I3)

Novamente a matematização vem à tona na fala de RRI - I3. Embora, inicialmente, não fosse a intenção do referido entrevistado, sua fala evidencia o papel da matemática, não somente como estruturador, mas também como elemento fundamental na validação cultural de um produto, qual seja: a própria ciência.

$\mathrm{Na}$ terceira questão foi solicitado aos entrevistados que sugerissem três temas/tópicos de FMC possíveis de serem trabalhados no EM e a fase ou momento curricular de sua inserção. Da compilação das respostas, uma característica detectada reforça a formação dos entrevistados, sobretudo quanto à estrutura curricular e os pré-requisitos. Dentre os 24 entrevistados que se manifestaram sobre esse questionamento, $83,3 \%$ deles sugeriram que tais temas só poderiam ser trabalhados no EM ao final do terceiro ano, devido sobretudo: "[...] à falta de maturidade dos alunos". (AEJ - I3), ou porque, "Os alunos estão mais espertos no final da terceira série". (AAA - I2).

Tais afirmações refletem uma "cultura" dos pré-requisitos. Porém, no que se refere a esta, Terrazzan (1994, p. 94) escreve: 
[...] existem sim os pré-requisitos de conteúdo, mas analisados a cada temática específica eles se revelarão sempre poucos e insuficientes para conformar de maneira tão decisiva as programações curriculares.

Ainda fazendo referência à questão 3, algumas contradições se fazem presentes. Conforme mencionado anteriormente, um número expressivo de entrevistados definiu o último ano do EM como sendo o momento mais adequado para tratar a FMC, por diversos fatores, dentre eles, e, sobretudo, o fator "Matemática".

"Só daria para fazer isso no final do $2^{\circ}$ grau, porque eles já tiveram um pouco de Matemática". $(\mathrm{ABC}-\mathrm{I} 1)$

"Como eu tinha dito. A Matemática é fundamental! [...] então eu acho que só épossivel no $3^{\circ}$ ano". (WPP - I2)

"Acho que só no final do terceiro ano [...] mesmo a gente sabendo que a matemática deles é fraca, até lá eles sabem alguma coisa". (LCC - I3)

Novamente a idéia suscitada anteriormente de que não é claro para os entrevistados o que seja formativo ou informativo é reforçada, visto que, se um percentual considerável deles elegeu a abordagem informativa como sendo a mais adequada, por que a preocupação com conceitos matemáticos ou com o momento em que os temas de FMC aparecerão na estrutura curricular?

Da síntese das declarações dos entrevistados, foi estruturada a Tabela 1, no que se refere à escolha de temas e tópicos de FMC possíveis de serem trabalhados no EM.

Embora não seja o objetivo deste trabalho efetuar uma profunda análise sobre as indicações de temas feitas pelos entrevistados, alguns elementos proveram mais recursos para esta discussão. Ao contrário das afirmações da maioria dos entrevistados que defendem uma abordagem mais informativa para os temas de FMC, muitas das sugestões de temas e tópicos indicadas por eles não podem ser tratadas informativamente, dada a complexidade conceitual.

Apesar de extensamente citados na Tabela 1, a radiação do corpo negro que trata da termodinâmica das radiações, o efeito fotoelétrico que trata da dualidade, e a relatividade que explora as relações de espaço-tempo não possuem entre si um vínculo conceitual direto, mas sua inclusão, frequentemente feita num percurso semi-histórico é necessária, caso se queira demonstrar a ruptura com a Física Clássica. Nesse caso, temas como estes não podem ser tratados informativamente. Entretanto, estes são os primeiros pontos propostos nos livros didáticos classicamente utilizados na formação de professores de Física.

De modo geral, os temas propostos na lista pelos entrevistados são aparentemente desconexos conceitualmente. Por exemplo, Raios-X, Laser, Partículas elementares, Radiações Nucleares formam um conjunto conceitualmente desconexo, o que dificulta a formulação de estratégias didáticas e a estruturação de propostas. É interessante analisar a dissonância entre os objetivos apregoados, tais como: discutir a visão de ciência, identificação de fenômenos de natureza quântica no dia-a-dia e na tecnologia, e as proposições de temas. Os dados obtidos indicam uma visão fragmentada da FMC, que pode estar refletindo características da formação inicial. 
Rezende Junior, M. F; De Souza Cruz, F. F.

Tabela 1. Temas e Tópicos de FMC para o Ensino Médio.

\begin{tabular}{|c|c|c|c|}
\hline & Tema 1 & Tema 2 & Tema 3 \\
\hline$A B C$ & Corpo Negro & Partículas elementares & Noções Eq. De Schrödinger \\
\hline APP & Raios-X & Laser & Radiação do Corpo Negro \\
\hline CCC & Efeito Fotoelétrico & Laser & Dualidade \\
\hline AAA & Átomo de Bohr & Corpo negro & Distribuição probabilística \\
\hline WPP & Radiações nucleares & Laser & Datação por Carbono 14 \\
\hline GGG & Corpo Negro & Efeito Fotoelétrico & Teoria Ondulatória da Matéria \\
\hline CLL & Astronomia: Marés & Astrofísica & Cosmologia \\
\hline PMM & Estrutura Atômica & Radiações & Radiação do Corpo negro \\
\hline DBB & Raios-X & Relatividade & Laser \\
\hline BBB & Laser & Corpo Negro & Raios-X \\
\hline SSA & Relatividade & Corpo Negro & Estrutura da Matéria \\
\hline AWW & Não é possível & Não é possível & Não é possível \\
\hline ESC & Astrofísica & Efeito Fotoelétrico & Modelos atômicos \\
\hline AEJ & Relatividade & Partículas & Laser \\
\hline ADD & Raios-X & Física Nuclear & Relatividade Restrita \\
\hline CDC & Efeito Fotoelétrico & Relatividade & Radiação do corpo negro \\
\hline EEE & Átomo de Bohr & Laser & Relatividade \\
\hline FCB & Relatividade & Modelos atômicos & Física Nuclear \\
\hline FBR & Relatividade & O Céu & Partículas Elementares \\
\hline JPD & Laser & Fibras Ópticas & Raios-X \\
\hline JRR & Astrofísica & Cosmologia & Dualidade \\
\hline LCC & Radiações & Corpo negro & Laser \\
\hline MDC & Relatividade Restrita & Relatividade Geral & Dualidade onda-corpúsculo \\
\hline ZAP & Física Nuclear & Relatividade & Efeito Fotoelétrico \\
\hline
\end{tabular}

Nota-se ainda que a lista de tópicos tem uma grande proximidade com os temas consensuais obtidos por Ostermann (1999), com uma população bem maior e que envolvia pesquisadores em Física e em Ensino de Física. Estas similaridades entre as duas listas são mais um indicativo do forte peso que tem a formação inicial na vida profissional dos professores de Física.

Embora os tópicos apresentados na tabela 1 reproduzam uma parcela do conteúdo programático dos cursos universitários, a desconexão conceitual e temática presente na lista mostra a dificuldade em definir, dentro da amplidão da FMC, um percurso conceitual e didaticamente estruturado que instrumentalize os alunos, tornando-os minimamente capazes de reconhecer e interpretar fenômenos da FMC. Além do mais, a contradição entre os objetivos mais amplos defendidos pelos entrevistados e os temas mostra uma lacuna entre estes objetivos e a sua formação. 
Também é preciso enfatizar que o tipo de listagem apresentada neste trabalho está longe de apontar caminhos ou dar indicativos do que deva ser tratado sobre FMC no EM, e que não está na lista um caminho para a inserção, mas sim, na busca de uma estrutura conceitual dentre os temas e tópicos sugeridos; nesse caso, a escolha dos temas tem uma relação mais forte com o que se objetiva com a FMC na escola básica, ou seja, formação e/ou informação. Evidentemente que a resposta a esse tipo de pergunta não é simples, sobretudo porque coloca em foco também os objetivos que se têm para a FMC na formação de professores de Física.

Dando sequência à análise, é preciso ressaltar que um dos aspectos recorrentes nas falas dos entrevistados foi a alusão frequente à matemática como um obstáculo, e que, em muitos momentos, os alunos entendem que o informativo está ligado à falta de matemática. Os entrevistados praticamente não fizeram menções explícitas ou referências diretas às dificuldades conceituais inerentes aos temas de FMC. Porém, a maioria dos temas sintetizados na Tabela 1 envolve conjecturas e interpretações, e, consequentemente, mobilizam conhecimentos diversos, o que obriga a existência de uma discussão, sobretudo conceitual e fenomenológica. Por outro lado, nota-se que, entre os temas mais sugeridos, encontram-se a Relatividade (Restrita), Átomo de Bohr e Efeito Fotoelétrico, cuja matemática não difere em nada da matemática associada à Física Clássica. Entretanto é necessário enfatizar que tais temas exigem um tratamento muito diferente daqueles dados a temas que didaticamente são tratados conforme a tradição, onde primeiramente se desenvolve a teoria, depois trabalham-se exemplos e, finalmente, aplica-se uma lista de exercícios. Isto indica que a matemática pode estar sendo usada como uma "fuga" e que o entendimento sobre as relações entre o formal e o conceitual no contexto da FMC não seja bem compreendido. Os resultados aqui apresentados indicam que é necessário investigar com mais profundidade a alegação de que a matemática é a grande vilã, pois, nos casos apresentados, não haveria razão aparente para tal afirmação.

$\mathrm{Na}$ quarta e última questão, foi apresentado um panorama hipotético para os entrevistados, aqui descrito: "Você está ministrando uma aula. Repentinamente um aluno lhe pergunta sobre os 'buracos de minhoca', sobre os quais o mesmo acabara de ler em uma revista de divulgação ${ }^{7}$ (exemplo: Revista Galileu). Você estaria preparado para lhe responder minimamente sobre o assunto? Em caso positivo, procure sintetizar em um esquema como abordaria tal assunto".

As respostas a essa última pergunta novamente demonstram contradições. Em relação à proposição acima, somente três licenciandos se declaram preparados, cada qual com seu motivo:

"Acho que sim, pois eu já preparei dois seminários sobre esse assunto durante o curso". (ABC - I1)

\footnotetext{
${ }^{7}$ A escolha do tema desta pergunta - "Buracos de Minhoca" - deu-se de forma completamente aleatória, em uma banca de revistas próxima ao local das primeiras entrevistas, por meio de materiais de divulgação científica atuais amplamente comercializados. $\mathrm{O}$ entrevistador, em um ato não planejado, abriu uma dessas revistas e escolheu o tópico com a melhor diagramação e arte. Tal tentativa teve o intuito de simular um estudante que tem nas mãos algum desses materiais, e que, por algum motivo, escolhe uma das matérias, a qual chama a sua atenção, seja pela temática tratada, seja pela beleza de sua apresentação gráfica.
} 
Rezende Junior, M. F; De Souza Cruz, F. F.

"Prontamente. Eu adoro astronomia, astrofísica e cosmologia". (CLL - I1)

"Estou fazendo as disciplinas do mestrado em Astrofísica aqui, e já cursei essa disciplina durante o curso [...]. O professor nunca explicou muito bem o que são os buracos, mas acho que eu conseguiria responder sim". (ZAP - I3)

Todos os demais assumiram não estarem minimamente preparados para tratar esse tipo de assunto com os alunos do EM. Inicialmente, tal fato não corresponde ao posicionamento dos entrevistados durante a primeira questão, onde os mesmos se declararam preparados para tratar temas mais modernos no EM.

"Sinceramente: acho que não sei nada sobre isso". (APP - I1)

"Precisaria estudar mais". (BBB - I1)

"Já ouvi falar, mas [...] não sei [...] precisaria estudar mais para não falar bobagem. (JPD - I3)

Propositadamente, nesta pergunta, para que se evitasse que os licenciados simplesmente respondessem que estão preparados para responder ou discutir sobre este assunto, foi adicionada a seguinte consideração: "em caso positivo, procure sintetizar em um esquema como abordaria tal assunto". Os dois entrevistados da I1, que se declararam preparados, ambos pediram papel e esquematizaram como poderiam abordar tal assunto. Por caminhos diferentes, sugeriram possibilidades de abordagem. A fala dos entrevistados ressalta a afinidade de ambos com o tema. Entretanto, declararam insatisfação quanto ao tratamento dado ao assunto no curso de licenciatura.

"Quando apresentei o seminário desse assunto foi muito legal, mas acho mesmo que o professor não queria falar sobre o assunto, então nos mandou dar os seminários. [...] depois eu aproveitei e apresentei o mesmo seminário em outra disciplina para aproveitar o trabalbão que tive”. (ABC - I1)

"Eu só acho que eu poderia saber um pouco mais, e en gostaria de saber um ponco mais, se os nossos professores discutissem sobre isso. [...] tudo que aprendi foi por conta". (CLL - I1)

Já o entrevistado ZAP - I3, declinou a respeito do pedido, dizendo que precisaria de tempo para realizar tal tarefa. Assim, somente entre os elementos pertencentes ao grupo daqueles que, na primeira pergunta, declararam-se preparados para tratar temas de FMC no EM, 9,52\% efetivamente reafirmaram diante do tema sugerido. No cômputo geral, eles seriam somente 6,45\%. Cabe ressaltar que temas como Relatividade Geral, Cosmologia e Astrofísica, que permeiam o tema escolhido "buracos de minhoca", estiveram presentes nas sugestões apresentadas na Tabela 1 para serem trabalhadas no EM - de um grande número de entrevistados durante a terceira pergunta da entrevista. 
Física moderna e contemporânea na formação ...

\section{Considerações finais}

Após a análise proposta, fica evidenciado que apesar da quase totalidade dos entrevistados demonstrarem interesse em levar a FMC para a escola média, suas declarações são motivo de preocupações, sobretudo no que tange à respectiva formação inicial; há uma indicação, por parte dos entrevistados, de que os conteúdos devam ser trabalhados no final do EM em função do nível cognitivo e maturidade dos alunos, o que pode refletir a cultura dos pré-requisitos e a tendência de repetição estrutural de sua formação, conforme já relatada em outros trabalhos, como os de Carvalho (1992) e Adams e Krockover (1997). Porém, se admitirmos a necessidade de conhecimentos prévios, a lista feita com temas conceitualmente desconexos e sem ordenamento conceitual nos indica que os entrevistados não têm clareza sobre quais efetivamente seriam os conhecimentos prévios necessários. Ademais, não é forçoso ressaltar que a disciplina Química, na escola básica, tem promovido tentativas nesta seara, ou seja, a introdução de FMC logo no início do EM. Sendo assim, a percepção de que os alunos necessitam maior maturidade também deve ser mais bem investigada.

Os entrevistados também demonstraram uma tendência a reproduzirem sua formação frente à possibilidade de implementação de tópicos e temas de FMC na escola média, mesmo que esboçando certa clareza de que não é possível ser feito algo com a mesma estrutura e forma com que fora apresentado nas respectivas disciplinas de graduação. Nesse caso, o questionamento que prevalece seria: como é possível levar a FMC para escola básica, já que, segundo Carvalho (1992), é uma prática comum o professor novato ir para a sala de aula e encontrar situações com as quais ele ainda não sabe lidar. $\mathrm{Na}$ falta de alternativas, busca nas práticas de seus ex-professores (mesmo que, quando na condição de aluno, não concordava com tais práticas) os exemplos para tratar determinadas situações. No caso da FMC, talvez a situação seja mais grave, pois geralmente os licenciandos têm uma carga horária média inferior em relação aos conteúdos clássicos, e uma profunda desarticulação para levar tais conteúdos à prática.

Em quase todas as entrevistas há indicações, e na maioria dos casos evidências explícitas, de que os conteúdos devam ser abordados com um caráter informativo, onde é citada, sobretudo, a deficiência da formação dos alunos da escola básica frente aos conhecimentos de Matemática. Outros indicam uma abordagem informativa como elemento de motivação e como forma de propiciar um maior entendimento nas leituras de revistas atuais. Mesmo assim, não se sentem preparados para responder minimamente sobre os "buracos de minhoca" - tema comumente presente em revistas de divulgação - julgando, na maioria dos casos, não terem tido contato com esse assunto durante o curso de formação.

Tal informação não deveria ser motivo de nenhum espanto, visto que, mesmo em relação a temas clássicos tradicionalmente trabalhados nas licenciaturas, observam-se resultados semelhantes. Longhini e Nardi (2003), ao entrevistarem licenciandos que cursavam a disciplina Prática de Ensino, sobre a construção de um plano de ensino referente ao tema Pressão Atmosférica, explicitam, em sua análise, que:

Os dados obtidos no questionário inicial mostram que a maior parte dos licenciandos analisados, apesar de cursar o último ano de licenciatura em Física, e portanto, prestes a estar 'aptos' a exercer a profissão, possuía um 
conhecimento do conteúdo específico próximo ao de alunos de nível médio. (LONGUINI e NARDI, 2003, p. 4)

Conforme afirmado anteriormente, quando se remete à FMC, os problemas têm implicações mais nocivas, visto que a mesma é praticamente inexistente no EM, sendo que alguns de seus tópicos e temas se fazem presentes caricatamente na disciplina de Química.

Outro ponto que ficou evidenciado nas entrevistas é o que trata da falta de material didático específico disponível ${ }^{8}$, embora os entrevistados reconheçam a existência de publicações específicas ${ }^{9}$, sendo que $77,4 \%$ dos entrevistados fizeram menção a esse fator. Entretanto, conforme mostrado acima, houve uma direta associação, por parte dos entrevistados das instituições 1 e 3, em vincular a possibilidade do tratamento dos temas e tópicos de FMC no EM à disponibilidade de recursos didáticos, entre eles, web, filmes, TV, softwares, mídias eletrônicas em geral.

Em relação a este ponto, destacamos o fato de que existiu uma forte tendência dos licenciandos a reproduzirem, ou minimamente associarem, conceitual e metodologicamente, o que foi desenvolvido em sua formação inicial nos espaços em que atuam ou que irão atuar como docentes. Como os entrevistados das I1 e I3 foram fortemente estimulados a tratar temas de FMC em disciplinas cujo objetivo central era o planejamento de tópicos/temas de Ciência e Tecnologia Contemporâneas e a seleção e produção de materiais didáticos com auxílio de multimeios, simulação e aplicação inicial em demonstrações/sala de aula, quando perguntados sobre a possibilidade de tratamento de FMC na escola média, a sua referência imediata era o estabelecimento do vínculo de que: "Para conseguir trabalhar com FMC na escola é preciso de computadores, internet, vídeos, etc" (JPD - I3). Esta constatação fica mais evidente quando, entre os cinco entrevistados da I2, nenhum deles estabeleceu tal vínculo em suas falas.

Esta análise pode, entretanto, tomar outras diretivas baseadas em um contraexemplo. E quando os licenciandos não têm, em suas disciplinas integradoras, um enfoque direcionado para tais tarefas? Suas referências únicas nos cursos de licenciatura seriam, então, as clássicas disciplinas de Estrutura da Matéria ou Introdução à Física Moderna? Então, por que os entrevistados não associaram a possibilidade de tratamento de FMC na escola média como um "espelho simplificado" dessas disciplinas classicamente cursadas?

Sobre esse ponto, é preciso enfatizar que, durante a formação inicial do licenciado, não é possível satisfazer todas as necessidades conceituais, experimentais, didáticas e metodológicas, o que geralmente é sentido durante a sua vida profissional. Contudo, durante as entrevistas realizadas, foi expressivo o número de entrevistados que ressaltaram o fato de que são necessários, durante a sua formação, além dos compromissos com as disciplinas estruturantes: a demonstração, a discussão e o enfrentamento por meio de "exemplares", que seriam adaptados em função da sua aplicação. E, indubitavelmente, é no período de formação

\footnotetext{
${ }^{8}$ Extraído das entrevistas como sendo, sobretudo, os livros didáticos.

${ }^{9}$ Foram mencionadas, notadamente, as publicações realizadas pela Sociedade Brasileira de Física, da série

"Temas atuais de Física". Para outras informações, acesse: http://www.sbfisica.org.br/ensino/index.shtml
} 
Física moderna e contemporânea na formação ...

inicial que respostas precisam ser dadas, pois "é nesta fase que a maioria dos licenciandos tem passado por um período de mudanças, ou seja, de alunos a professores" (CAMARGO e NARDI, 2003, p. 35).

A situação relatada, cujos dados foram apresentados, pode ser um caso mais grave quando se leva em consideração o fato de que a carga horária disponível para disciplinas em que o foco seja a Física do século XX, nos cursos de licenciatura, é reduzida. Assume-se aqui o posicionamento de que disciplinas integradoras, como Instrumentação para o Ensino de Física, Metodologia de Ensino de Física etc, podem e devem assumir tal papel, colaborando diretamente com disciplinas de cunho estruturante, como Estrutura da Matéria e Laboratórios Adjacentes, no intuito de fortalecer a formação de licenciandos para o cumprimento mínimo de suas funções como professor.

Tal consideração ainda demanda investigações em outros cenários, tanto teóricos quanto aplicados, embora sejam relevantes e impactantes de forma direta e imediata nos Cursos de Licenciatura, pois, conforme já argumentaram Camargo e Nardi (2003, p.35), “a profissionalização do professor não finda ao término do curso, mas prolonga-se ao longo de sua carreira, decorrente de toda a experiência adquirida enquanto aluno, bem como no transcorrer da prática profissional". Assim, a formação inicial de professores de Física, que passa por mudanças estruturais na atualidade, carece de um constante diálogo com a pesquisa em Ensino de Física.

No estudo aqui apresentado, há uma clara indicação, por parte dos entrevistados, de que os conteúdos devam ser trabalhados no final do EM em função do nível cognitivo e maturidade dos alunos. De uma forma superficial, os entrevistados também mostraram uma tendência a reproduzirem sua formação quanto à possibilidade de implementação de tópicos e temas de FMC na escola média, mesmo tendo clareza de que não é possível ser feita da mesma forma como lhes fora apresentada durante sua formação inicial. Da mesma forma, é necessário investigar em maior profundidade a alusão frequente da matemática como obstáculo à inserção da FMC.

Finalizando, na perspectiva dos entrevistados, há indícios de que não existe um consenso do que venha a ser formativo ou informativo frente aos objetos de ensino correspondentes a temas de FMC e, sendo assim, os dados aqui apresentados podem ajudar a fomentar a discussão sobre a formação de professores de Física, seja para intervenções no âmbito inicial ou continuado.

\section{Referências}

ADAMS, P. E.; KROCKOVER, G. H. Beginning science teacher cognition and its origins in the preservice secondary science teacher program. Journal of Research in Science Teaching, Maryland, v. 34, n. 6, p. 633-53, 1997.

ARONS, A. B. A guide to introductory physics teaching. New York: John Wiley, 1990.

BRASIL. Lei n. 9.394, de 20 de dezembro de 1996. Lei Darcy Ribeiro. Estabelece as Diretrizes e Bases da Educação Nacional. Diário Oficial [da] República Federativa do Brasil, DF, 23 de dezembro de 1996, v. 134, n. 248, p. 27833-41, Seção 1. 
Rezende Junior, M. F; De Souza Cruz, F. F.

BRASIL. Ministério da Educação e do Desporto. Secretaria da Educação Média e Tecnológica. Parâmetros Curriculares Nacionais: Ensino Médio. Brasília: Ministério da Educação, 1999.

CAMARGO, S.; NARDI, R. Formação de professores de Física: os estágios supervisionados como fonte de pesquisa sobre a prática de ensino. Revista Brasileira de Pesquisa em Ensino de Ciências, Bauru, v. 3, n. 3, p. 34-55, 2003.

CARVALHO, A. M. P. Reformas nas licenciaturas: a necessidade de uma mudança de paradigma mais do que de mudança curricular. Em Aberto, Brasília, v. 11, n. 54, p. 51-63, 1992.

FISCHLER, H.; LICHTFELDT, M. Modern physics and student's conception. Internacional Journal of Science Education, London, v. 14, n. 2, p. 181-90, 1992.

GIL, D.; SOLBES, J. The introduction of modern physics overcoming a deformed vision of science. International Journal of Science Education, London, v. 15, n. 3, p. 255-60, 1993.

GRECA, I. M. Construindo significados em mecânica quântica: resultados de uma proposta didática aplicada a estudantes de física geral. 2000. 248f. Tese (Doutorado em Ciências) - Instituto de Física, Universidade Federal do Rio Grande do Sul, Porto Alegre, 2000 .

LOBATO, T.; GRECA, I. M. Análise da inserção de conteúdos de Teoria Quântica nos currículos de Física do Ensino Médio. Ciência \& Educação, Bauru, v. 11, n. 1, p. 119-32, 2005.

LONGHINI, M. D.; NARDI, R. Formação inicial de professores - uma estratégia envolvendo a Prática de Ensino de Física. In: ESCOLA DE VERÃO PARA PROFESSORES DE PRÁTICA DE ENSINO DE BIOLOGIA, FÍSICA, QUÍMICA E ÁREAS AFINS, 6., 2003, Niterói. Atas... Niterói, 2003. 1 cd-rom.

LÜDKE, M.; ANDRÉ, M. E. D. A. Pesquisa em educação: abordagens qualitativas. São Paulo: EPU, 1986.

MACHADO, D. I.; NARDI, R. Construção e validação de um sistema hipermídia para o ensino de Física Moderna. Revista Electrónica de Enseñanza de las Ciencias, v. 6, n.1, p. 90-116, 2007. Disponível em: http://www.saum.uvigo.es/reec/. Acesso em: 2 abr. 2008.

MOTA, L. M. As controvérsias sobre a interpretação da mecânica quântica e a formação dos licenciados em Física (um estudo em duas instituições: UFBA e UFSC). 2000. 176f. Dissertação (Mestrado em Educação) - Centro de Educação, Universidade Federal de Santa Catarina, Florianópolis, 2000.

OSTERMANN, F. Tópicos de física contemporânea em escolas de nível médio e na formação de professores de Física. 1999. 162f. Tese (Doutorado em Ciências) - Instituto de Física, Universidade Federal do Rio Grande do Sul, Porto Alegre, 1999. 
Física moderna e contemporânea na formação ...

OSTERMANN, F.; MOREIRA, M. A. Uma revisão bibliográfica sobre a área de pesquisa física moderna e contemporânea no Ensino Médio. Investigações em Ensino de Ciências, Porto Alegre, v. 5, n. 1, p. 23-48, 2000. Disponível em: <http://www.if.ufrgs.br/ public/ensino>. Acesso em: 05 mar. 2008.

OSTERMANN, F.; RICCI, T. F. Construindo uma unidade didática conceitual sobre mecânica quântica: um estudo na formação de professores de Física. Ciência \& Educação, Bauru, v. 10, n. 2, p. 235-57, 2004.

; __ Conceitos de física quântica na formação de professores: relato de uma experiência didática centrada no uso de experimentos virtuais. Caderno Brasileiro de Ensino de Física, Florianópolis, v. 22, n. 1, p. 9-35, 2005.

REZENDE JR., M. F. O processo de conceitualização na formação inicial de professores de Física. 2006. 250f. Tese (Doutorado em Educação Científica e Tecnológica) - Centro de Ciências Física e Matemáticas, Universidade Federal de Santa Catarina, Florianópolis, 2006.

.; DE SOUZA CRUZ, F. F. Física moderna e contemporânea no Ensino Médio: formação ou informação. In: ENCONTRO NACIONAL DE PESQUISA EM EDUCAÇÃO EM CIÊNCIAS, 5., 2005, Bauru. Atas... Bauru: ABRAPEC, 2005. 1 cd-rom.

RICARDO, E. C. As Ciências no Ensino Médio e os Parâmetros Curriculares Nacionais: da proposta à prática. Ensaio: Avaliação e Políticas Públicas em Educação, Rio de Janeiro, v. 10, n. 35, p. 141-60, 2002.

.; ZYLBERSTAJN, A. O ensino das Ciências no nível médio: um estudo sobre as dificuldades na implementação dos Parâmetros Curriculares Nacionais. Caderno Brasileiro de Ensino de Física, Florianópolis, v. 19, n. 13, p. 351-70, 2002.

TERRAZZAN, E. A. Perspectivas para a inserção da física moderna na Escola Média. 1994. 241f. Tese (Doutorado em Educação) - Faculdade de Educação, Universidade de São Paulo, São Paulo, 1994.

Artigo recebido em dezembro de 2008 e aceito em junho de 2009. 